\title{
A FORÇA DOS PRECEDENTES NO JULGAMENTO DE SHYLOCK EM O MERCADOR DE VENEZA DE SHAKESPEARE
}

\author{
Gustavo SANTANa NogUeira ${ }^{1}$
}

\begin{abstract}
RESUMO: O trabalho se dispõe a apresentar a força dos precedentes judiciais através do exame da obra $O$ mercador de Veneza, de Shakespeare, uma vez que a teoria dos precedentes vinculantes, originariamente conhecida como stare decisis, tem sua origem no direito britânico. Pretende-se abordar, ainda que brevemente, a história dos precedentes no seu nascedouro, traçando um paralelo entre a cultura jurídica britânica e a peça acima referida, numa perspectiva histórica. Observar-se-á que, na época em que a peça foi escrita pelo dramaturgo de Stratford-upon-Avon, já havia uma cultura judicial em torno dos precedentes, como o comprova a análise de decisões judiciais contemporâneas ao período em que a peça teria sido provavelmente escrita. O foco específico é o trecho do famoso julgamento da execução da garantia da nota promissória, que autorizava o credor a cortar uma libra de carne do devedor, em que Pórcia, uma das personagens, afirma: "Impossível; não há poder em Veneza que possa alterar um decreto sacramentado. Ficaria registrado como um precedente, e muitas ações legais equivocadas, uma vez dado esse exemplo, choveriam sobre o Estado. Impossível”. Já na Inglaterra medieval verifica-se claramente - e a obra de Shakespeare o evidencia - a importância dos precedentes judiciais, bem como a sua relevância para pautar a conduta dos cidadãos em suas relações fora do Judiciário, inclusive. A fala sugere que uma decisão judicial gera proteção de confiança e expectativa legítima, não só para as partes do caso concreto, mas para a sociedade como um todo.
\end{abstract}

PALAVRAS-CHAVE: Shakespeare; $O$ mercador de Veneza; precedentes; stare decisis; common law.

\section{INTRODUÇÃO}

O presente trabalho se dispõe a apresentar a força dos precedentes judiciais através da obra $O$ mercador de Veneza, de Shakespeare, uma vez

1 Doutor em Direito pela Universidade do Estado do Rio de Janeiro (UERJ). Professor de Direito Processual Civil na Universidade de Barra Mansa (UBM). Promotor de Justiça RJ. Rio de Janeiro, RJ, Brasil. CV Lattes: http://lattes.cnpq.br/4509486529223924. Email: gustavonogueira75@terra.com.br 
que a teoria dos precedentes vinculantes, originariamente conhecida como stare decisis, tem sua origem no direito britânico. Pretende-se analisar, no segundo capítulo, a história dos precedentes no seu nascedouro, traçando um paralelo entre a cultura jurídica britânica e a peça acima referida. Observar-se-á que, na época em que a peça foi escrita pelo dramaturgo de Stratford-upon-Avon, já havia uma cultura judicial em torno dos precedentes, o que se verifica através da análise de decisões judiciais contemporâneas ao período em que a peça teria sido provavelmente escrita. $\mathrm{Na}$ terceira parte, o foco específico é o trecho do famoso julgamento da execução da garantia da nota promissória, que autorizava o credor a cortar uma libra de carne do devedor, em que Pórcia, uma das personagens, afirma: "Impossível; não há poder em Veneza que possa alterar um decreto sacramentado. Ficaria registrado como um precedente, e muitas ações legais equivocadas, uma vez dado esse exemplo, choveriam sobre o Estado. Impossível”. Na quarta parte, será observado que já na Inglaterra medieval verificava-se claramente, como evidenciado pela obra de Shakespeare, a importância dos precedentes judiciais, bem como a sua relevância para pautar a conduta dos cidadãos em suas relações fora do Judiciário, inclusive. A fala sugere que uma decisão judicial gera proteção de confiança e expectativa legítima, não só para as partes do caso concreto, mas para a sociedade como um todo, gerando segurança jurídica. Tanto na common law como na civil law, a segurança jurídica é um valor fundamental do ordenamento jurídico, porém a pesquisa limita-se a analisar a referida segurança exclusivamente através dos precedentes. Ao final, serão tecidas as considerações conclusivas.

\section{A ORIGEM DA FORÇA DOS PRECEDENTES: INGLATERRA}

Para os propósitos deste trabalho, a história do direito britânico pode começar a ser contada a partir de 1066, quando Guilherme, o Conquistador (Willian, the Conqueror), saiu da Normandia e invadiu a ilha, sagrando-se vencedor na Batalha de Hastings. Atualmente, sabe-se que os normandos na Inglaterra não eram numerosos e que o (novo) Rei Guilherme não mostrou nenhum desejo de impor aos seus novos súditos qualquer código estrangeiro, até porque não havia códigos na Normandia. A lei normanda não foi levada para a Inglaterra, de modo que prevaleceu o direito inglês 
(Pollock; Maitland, 1898, p. 79). E no antigo direito inglês, como acentuam os autores citados, muitas regras foram deixadas para o costume da sociedade; regras essas que, atualmente, são previstas na legislação e controladas por tribunais (1898, p. xciv), porém é de se observar que mesmo antes de 1066 havia um "direito" vigente na Inglaterra, produzido durante o reinado dos antigos reis e compilado na obra Tractatus de priscis Anglorum Legibus, de William Lambard, de 1313, o que mostra que mesmo os costumes (leges non scriptae) eram redigidos para não se perderem no tempo (Hale, 1971, p. 3-5).

Ainda no século XIII, o juiz Henry de Bracton (1210-1268) foi capaz de formular uma doutrina de precedentes num tratado que contém referências acerca de 2.000 casos e no qual ele afirmava que se nenhuma circunstância, nova ou rara, aparecesse em determinado caso concreto, ele devia ser julgado de forma semelhante a algum caso anterior, porque seria uma boa oportunidade para proceder da mesma maneira. Segundo Arthur Hogue (1985), o juiz Bracton era uma exceção na época, já que não havia ninguém que fizesse referência aos casos anteriores - os precedentes como ele. Mas a vinculação aos precedentes não era exatamente como hoje se conhece, porque as citações feitas no compêndio de Bracton eram apenas para ilustrar ou explicar o direito. Segundo Hogue:

As citações são genéricas às vezes e estão em frases no sentido de que "temos visto frequentemente" ou "foi decidido antes deste" ou "está em nossos livros". Os juízes na Idade Média eram obrigados a mirar nenhum padrão mais elevado do que a consistência judicial (1985, p. 201).

Ademais o acesso aos plea rolls era quase impossível, não sendo possível aos litigantes e nem mesmo os advogados, e mesmo aqueles que podiam consultar os rolos - os juízes, por exemplo - não tinham o hábito de neles procurar princípios jurídicos. Raros e específicos precedentes podem ter sido alegados nos Tribunais, e durante o reinado de Edward I (1239-1307) os litigantes já estavam citando e distinguindo casos anteriores; porém, como regra geral, os juízes, assistidos por funcionários, que seriam os futuros juízes, consideravam-se como tendo um conhecimento implícito do curiae consuetudo (costume ou prática da Corte) e não se sentiam obrigados a discutir sobre casos passados. Eles tinham a presunção de que conheciam o direito, em razão da experiência, porque na época entendia-se que todo homem que ocupava uma função 
dessas conhecia grande quantidade de leis e costumes. Segundo Pollock e Maitland:

O costume da Corte do Rei é o costume da Inglaterra, e torna-se o direito comum (common law). Como os costumes locais, os juízes do Rei iriam a frases gerais expressar seu respeito por eles. Nós não vemos nenhum sinal de qualquer desejo consciente concebido para extirpá-los (1898, p. 184).

Atualmente, no século XXI, os precedentes alcançaram um patamar bem diferente. Hoje é absolutamente natural encontrar-se em decisões judiciais citações a precedentes, porque os precedentes são a "chave do raciocino jurídico inglês” (Cownie et al., 2007, p. 86). Porém, naquela época - Idade Média -, os precedentes até eram encontrados em plea rolls (uma espécie de rolo em que os casos eram registrados), mas os advogados não buscavam nesses registros os casos anteriores para reforçar os seus argumentos em uma causa. Segundo Neil Duxbury os plea rolls continham os casos anteriores, mas não as razões pelas quais os casos foram julgados (ratio decidendi), que não eram parte dos registros. Ademais, prossegue, "embora os tribunais ocasionalmente seguissem e até mesmo distinguissem precedentes, ninguém ainda acreditava que um tribunal poderia ser vinculado por uma decisão anterior" (Duxbury, 2008, p. 32).

Há inclusive quem afirme ainda que Henry de Bracton, apesar do seu tratado compilando precedentes da Court of Common Pleas, o historicamente famoso Note Book ${ }^{2}$, tinha como intenção real ensinar os jovens estudantes de direito da época acerca dos princípios jurídicos, e a solitária busca que ele fez nos plea rolls (extensos rolos de julgados sem índice ou qualquer outra forma de ajudar a pesquisa do seu conteúdo) levou para o note book apenas os casos por ele selecionados. Ele foi o único a fazer isso: acessar os rolos e transcrever para o seu livro os casos já julgados, que ele selecionava por conta própria e, supostamente, utilizava casos antigos e superados para a época, e por isso há quem negue - como Theodore Plucknett - que ele tenha feito isso com a intenção de estabelecer uma coletânea de precedentes para utilização futura pelos juízes (Plucknett, 1956, p. 380).

2 Uma versão do Note Book, publicada em 1887, pode ser encontrada online em: <https://archive.org/details/bractonsnoteboooomaitgoog>. Acesso em: 19 ago. 2016. 
Portanto há um consenso na doutrina de que, apesar da compilação levada a efeito por Bracton, não se podia falar em um sistema de precedentes vinculantes na Inglaterra do século XIII. Theodore Plucknett nos revela que, em 1310, um juiz chamado Bereford fez referência à força dos precedentes, afirmando que uma decisão deveria valer como lei perante toda a nação, mas também observa que foi um caso "isolado", porque o costume - que era enunciado pelas decisões judiciais das Cortes - tinha como característica a facilidade com que surgia e era alterado (Plucknett, 1956, p. 382).

Só se pode realmente começar a mencionar os precedentes como algo relevante para o direito na common law a partir do século $\mathrm{XV}$, com o surgimento dos Year Books, um livro que efetivamente compilava os precedentes das Cortes, mas ainda nessa época não havia nada parecido com os precedentes vinculantes de hoje (Cross; Harris, 2004, p. 24).Um único caso não era considerado vinculante para juízes de casos futuros, mas um costume bem estabelecido (comprovado através de muitas ou poucas citações casuais dos casos) era, sem dúvida, considerado como altamente persuasivo, como observado por Plucknett, o que começou a mudar após o século XVI (Plucknett, 1956, p. 384-385).

Foi apenas na virada do século XVI para o XVII - na mesma época de Shakespeare - que pela primeira vez se considerou que uma única decisão da Exchequer Chamber serviria como precedente obrigatório para casos futuros. Conforme Plucknett:

\begin{abstract}
[...] no século XVII foi estabelecido que uma decisão da Exchequer Chamber era um precedente vinculante. Coke afirmou que a resolução de todos os juízes era quase tão alta quanto uma lei (statute). Bacon insistiu que mesmo o chancellor se renderia à opinião de todos os juízes, e em 1602 uma decisão da Chamber foi referida como uma "determinação de todos os juízes da Inglaterra", que "era para ser um precedente para todos os casos subsequentes". Em 1686 Herbert, Chief Justice, anunciou como "uma regra conhecida que, após qualquer questão de direito ter sido solenemente decidida na Exchequer Chamber por todos os juízes, nós nunca experimentaremos ter essa questão contestada novamente" (1956, p. 384-385).
\end{abstract}

Resta analisar se exatamente no período em que Shakespeare viveu (1564-1616) havia a cultura do precedente vinculante, e nada melhor do que fazer essa análise através de Sir Edward Coke (1552-1634), que foi Chief 
Justice na Court of Common Pleas, entre 1606 e 1613. Coke se notabilizou por alguns feitos, notadamente a decisão proferida no Bonham's Case, de 1610. Em trabalho publicado anteriormente já havíamos destacado a razão pela qual a referida decisão é histórica:

Um trecho da paradigmática decisão tornou-se notório,
pelo fato de estar ali esboçado o início do controle de
constitucionalidade das leis e de atos administrativos,
pois havia sido questionada a autoridade do Royal
College de julgar, intimar e ainda receber o dinheiro
proveniente da aplicação das multas. [...]
"And it appears in our books, that in many cases, the
common law will controul [sic] acts of parliament, and
sometimes adjudge them to be utterly void: for when an
Act of parliament is against common right and reason, or
repugnant, or impossible to be performed, the common
law will controul it, and adjudge such Act to be void"
(Nogueira, 2010, p. 310)3.

Coke foi um defensor da força vinculante dos precedentes, e no trecho mais célebre da histórica decisão ele afirma: "and it appears in our books, that in many cases", ou seja, está nos "nossos livros" e "em vários casos". Que livros seriam esse, se não os Years Books? E que vários casos eram esses, senão casos julgados antes da sua própria decisão, ou seja, alguns precedentes?

É importante destacar que Sir Edward Coke já havia feito uso de precedentes anteriormente para fundamentar suas decisões, como no Calvin's Case, em 1608. Após o Rei Jaime VI, da Escócia, assumir o trono inglês pelo falecimento da Rainha Elizabeth I e se tronar o Rei James I da Inglaterra, houve a unificação dos reinados, e nessa decisão Coke considera que uma criança nascida na Escócia estava sujeita ao common law e aos direitos que ele assegurava. Para julgar esse caso, Coke fez uso de precedentes (Hulsebosch, 2003, p. 446). No Bonham's Case, ele cita alguns precedentes medievais, como razões de decidir (Coke, 1826, p. 355-383). A doutrina observa uma divergência acerca da adequação dos precedentes invocados por Coke para justificar racionalmente o julgado no Bonham's Case, que estatuiu a superioridade da common law sobre os atos do Parlamento, havendo aqueles que defendem que tais precedentes não

3 Tradução livre: "e parece, nos nossos livros, que em muitos casos, o common law controlará as leis, e, por vezes, as declarará nulas: pois, quando um ato legislativo for contrário ao Direito e à razão comum, ou repugnante, ou impossível de ser aplicado, o common law o controlará, e o declarará nulo”. 
serviriam exatamente para o caso concreto. Mas o fato é que - bem ou mal - os precedentes foram invocados por Coke para justificar a sua decisão no Bonham's Case, de 16104. Segundo Francisco Fernandez Segado, Coke nunca duvidou da força vinculante da legislação [direito positivo], mas ele visualizou a lei estatutária [direito estatutário] que emana do Parlamento dentro do contexto histórico dos precedentes dos tribunais ingleses da common law (Segado, 2013, p. 188).

Pode-se verificar que, na mesma época de Shakespeare, o juiz Coke, da Court of Common Pleas, fazia uso dos precedentes em seus julgados, como se de fato estivesse vinculado às razões das decisões anteriores. $\mathrm{E}$ para os fins deste trabalho é irrelevante o fato dos precedentes medievais invocados por Coke terem ou não adequação com a sua sentença em Bonham's Case. Atualmente dispõe-se de uma série de obras, ensinamentos doutrinários e também decisões judiciais esmiuçando a teoria dos precedentes vinculantes (stare decisis et non quieta movere), inclusive os institutos a ela inerentes, e mesmo assim, até hoje, equívocos são cometidos. Difícil deve ter sido fazer isso no século XIV, sendo praticamente o pioneiro.

Nessa época, não custa lembrar, Shakespeare já estava em plena atividade, produzindo peças e eventualmente nelas atuando como ator, e inclusive a expressão "precedente" - que figura em O mercado de Veneza foi notada pela primeira vez em 1557, segundo Sir Carleton Allen (Plucknett, 1956, p. 385). Tudo indica, assim, que William Shakespeare sabia exatamente o que estava fazendo quando usou a expressão "precedente" aproximadamente 40 anos depois, e inclusive seu emprego por Shakespeare, como será visto adiante, foi juridicamente perfeito e revelou não uma coincidência, mas sim uma visão muito além do seu tempo.

\section{OS PRECEDENTES EM O MERCADOR DE VENEZA}

$\mathrm{Na}$ famosa obra $O$ mercador de Veneza, escrita provavelmente entre 1596 e 1598, o dramaturgo William Shakespeare, nascido em Stratford-

\footnotetext{
4 Segado analisou todos os precedentes - Thomas Tregor's Case, Cessavit 42, Annuity 41 e Strowd's Case - e concluiu que apenas o caso Cessavit 42 apresenta-se como um sólido precedente para a fundamentação da decisão de Coke (Segado, 2013, p. 212).
} 
upon-Avon, na Inglaterra, escreveu uma cena muito conhecida: o julgamento da execução da garantia da nota promissória que Antônio, o mercador, devia a Shylock, o judeu ${ }^{5}$. Nela estava prevista a possibilidade de Shylock cortar uma libra de carne do devedor, e nada mais, a título de multa, razão pela qual não foi possível ao credor receber a carne, porque "a promissória não prevê que te apropries do sangue do mercador. As palavras dizem expressamente uma libra de carne". Além desse famoso trecho, em que se faz uma interpretação jurídica fartamente estudada e debatida pelos juristas 6 , como André Karam Trindade7, há outras que são pertinentes ao objeto deste estudo. Salarino, amigo de Antonio, conforta-o dizendo que o Doge de Veneza não irá considerar válido o contrato, no que ele responde: “o doge não pode impedir o curso da lei”. Em outras palavras, se a lei estabelece ser direito de Shylock a execução da garantia, a decisão do Doge (juiz) não pode ser contrária à lei, porque isso iria gerar um efeito negativo em toda a sociedade. A preocupação de Antonio com os reflexos de uma decisão ilegal, ainda que capaz de salvar a sua vida, fica evidente na $3^{\mathrm{a}}$ cena do Ato III:

porque existem os benefícios de que gozam os estrangeiros conosco aqui em Veneza; uma vez não se cumprindo a lei, cai em descrédito a justiça no nosso Estado; uma vez que o comércio e os lucros da cidade acolhem igualmente todas as nações (Shakespeare, 2010, p. 89).

Um pouco antes do veredito, é proposto por Bassânio o pagamento da dívida representada pela nota promissória, em dinheiro vivo, o valor em dobro e até mesmo dez vezes o valor original. Bassânio pede ao seu advogado, Dr. Baltasar, que era Pórcia, outro personagem, disfarçada de advogado $^{8}$, para convencer Shylock a aceitar o pagamento e, assim, fazer um "enorme bem e um mal mínimo", perdoando a multa.

5 Mesmo aqueles que não são da área do direito reconhecem que "a grande cena do julgamento é em si um notável exemplo da questão da justiça e das leis" (Heliodora, 2014, p. 123).

6 A esse respeito, sugerimos ver Fragale Filho e Lynch (2008).

7 Sobre o tema, Trindade destaca que, "Ao que tudo indica, na verdade, esta peça de Shakespeare - apesar da distância temporal de sua produção - revela, de um modo especial, que não existe 'a lei', mas apenas 'a lei interpretada', colocando um problema hermenêutico, visto que o caso instala um conflito de interpretações” (Trindade, 2015, p. 180).

8 Há controvérsia inclusive sobre o papel que Pórcia (Dr. Baltasar) exerce no julgamento. A afirmação de que se tratava de um advogado decorre do fato de Antonio e Bassânio, ao 
Pórcia se recusa, nos seguintes termos: "Impossível; não há poder em Veneza que possa alterar um decreto sacramentado. Ficaria registrado como um precedente, e muitas ações legais equivocadas, uma vez dado esse exemplo, choveriam sobre o Estado. Impossível" (Shakespeare, 2010, p. 105). Na versão original em inglês medieval, publicada em 1600, a expressão "ficaria registrado como um precedente" aparece como "twill be recorded for a precedent” ${ }^{9}$. Já em inglês contemporâneo:
It must not be. There is no power in Venice
That can reverse an established decree.
'Twill then be counted as a precedent,
And many an error, by the same example,
Will rush into the state. It cannot be (Shakespeare, 2015, p. 149).

Pórcia poderia ter tentado convencer Shylock e o Doge a aceitar o pagamento em dinheiro, fazendo a valoração dos princípios jurídicos atinentes ao caso, como a justiça do que foi acordado entre as partes, afinal o corte da libra de carne do devedor, além de matá-lo, era apenas a multa para o caso de não pagamento, e, apesar do pagamento não ter sido realizado no prazo, estava sendo oferecido entre o dobro e dez vezes o valor da dívida, quitando-a e extinguindo a obrigação. Talvez não fosse problema deixar registrado como precedente a possibilidade de o devedor pagar de duas a dez vezes o valor da dívida, até porque a interpretação literal da "libra de carne" sem o sangue do devedor fez com que, ao final, Shylock não recebesse o valor da dívida e ainda perdesse parte considerável do seu patrimônio, por força das leis vigentes na época.

Porém, Pórcia rejeitou a possibilidade do pagamento com o argumento de que a sua decisão, permitindo o pagamento e não a execução da garantia, iria criar um precedente e esse precedente, com efeito vinculante perante os juízes, repercutiria negativamente em toda a sociedade, tendo como resultado uma "chuva de ações legais equivocadas". Esse pequeno fragmento da obra shakespeariana nos revela uma situação

final, lhe proporem o pagamento de honorários. Há quem afirme que a função era de amicus curiae, mesmo reconhecendo o absurdo da proposta de pagamento (Neves, 2016, p. 145 e 162).

9 A versão original, publicada no Primeiro Quarto, em 160o, encontra-se online, no sítio eletrônico da British Library. Segundo o site, a peça $O$ mercador de Veneza, na primeira edição, apareceu em 1600, impresso por James Roberts a pedido de Thomas Heyes. Disponível em: <http://special-1.bl.uk/treasures/shakespeare/merchantbibs.html\#first $>$. Acesso em: 19 ago. 2016. 
bastante interessante: a sociedade inglesa, entre os anos de 1596 e 1598, pautava suas condutas pelos precedentes, e essa é uma máxima da teoria dos precedentes que hoje se defende inclusive em países da família civil law: é importante respeitar os julgados anteriores porque eles determinam condutas nas relações extrajudiciais, gerando previsibilidade e segurança. $\mathrm{O}$ próprio Shylock, questionado pelo Doge acerca da sua recusa em aceitar o pagamento e insistência em receber a libra de carne como multa, argumenta:

Essa uma libra de carne que exijo dele foi comprada a peso de ouro; ela é minha, e vou levar o que é meu. Se isso me for negado, meus senhores, as suas leis são uma vergonha; os decretos de Veneza não são respeitados. Estou aqui para um julgamento. Quero que me respondam: terei o meu julgamento? (Shakespeare, 2010, pp. 100-101).

Shylock defende a necessidade de se ter um julgamento em que as leis são aplicadas e alerta que, caso isso não ocorra, a decisão judicial será motivo de "vergonha", passando para a sociedade veneziana - na verdade inglesa - a impressão de que o direito não é respeitado. Movido por intenso desejo de vingança, nota característica das obras shakespearianas ${ }^{10}$,ele pede o julgamento na certeza de que a lei será aplicada, e, a partir do momento em que se tem uma decisão judicial, cria-se um precedente que pauta a conduta da sociedade, sendo uma "vergonha" o desrespeito decorrente da não aplicação ${ }^{11}$.

É também a mesma visão que Pórcia demonstra ao se recusar a propor o descumprimento do acordo, ainda que a sua execução seja uma medida muito injusta, porque poderia gerar um precedente perigoso o suficiente para fazer com que as pessoas buscassem no Judiciário o não cumprimento das obrigações assumidas por razões diversas. Junte-se, pois, o precedente que "autoriza" o desrespeito aos acordos à "chuva" de ações que deveriam ser julgadas de acordo com o precedente Shylock $v$. Antonio e

10 Cabe referir, aqui, a explicação oferecida por Ghirardi: "O tema da vingança expandia o paradoxo cristão ao estabelecer uma tensão entre Direito e Natureza e ao tornar evidente a difícil coexistência entre os impulsos do homem natural, a racionalidade do bom súdito e a abnegação do bom cristão: não parece surpreendente que as plateias da época fossem apaixonadas por esse tema" (Ghirardi, 2015, p. 88).

11 Observe-se que André Karam Trindade chama a atenção para o fato de o julgamento em si ser uma "farsa desde o seu início", uma vez que Pórcia "conduz o caso litigioso com a finalidade de salvar o amigo de seu amado" (Trindade, 2015, p. 176). 
ter-se-á a "vergonha" decorrente da falta de eficácia do direito vigente. É uma interpretação totalmente plausível que revela não só a genialidade de Shakespeare em antecipar questões que somente viriam a ser discutidas séculos depois, mas também a cultura dos precedentes na common law.

Essa observação é confirmada por Kenji Yoshino, quando analisa o direito e a prática judiciária na Inglaterra da época:

Quando Shakespeare escreveu $O$ mercador, o rigor das promissórias estava sendo desafiado de maneira vigorosa e bem-sucedida. Indivíduos compelidos por tais instrumentos apelavam ao rei por meio do Supremo Tribunal. Este não podia anular a promissória, mas podia acolher um pedido, conhecido como injunção, que proibia que o cobrador a executasse. Por volta de 1590, as intervenções do Supremo Tribunal eram rotina (Yoshino, 2014, p. 45).

$\mathrm{Na}$ época de Shakespeare os teatros eram muito populares, e o autor não tinha formação jurídica, porém esse simples trecho da fala de Pórcia, o "doutor em Direito" no julgamento de Shylock, nos revela como a cultura dos precedentes existe na Inglaterra há séculos. Apesar do enredo da obra se situarem Veneza, os especialistas em Shakespeare afirmam que ele nunca saiu da Inglaterra ${ }^{12}$, de modo que sua peça era ambientada na Itália, porém ela foi escrita por um inglês, na Inglaterra, e para ser representada em palcos ingleses. Outra leitura possível é de que "a peça passa-se em Veneza porque a cidade era uma das poucas da Europa Ocidental que não havia expulsado os judeus" (Yoshino, 2014, p. 43). Entretanto, o que parece consenso entre os especialistas em Shakespeare é que $O$ mercador de Veneza foi inspirado mesmo em um conto medieval chamado Il Pecorone, de Ser Giovanni Fiorentino, publicado em 1558, em Milão. De acordo com Barbara Heliodora, "a maior parte do enredo ele tira da história do jovem Gianetto, que aparece como a primeira no quarto dia de uma coletânea de novelle intitulada Il Pecorone (O Simplório), de um tal Ser Giovanni Fiorentino" (Heliodora, 2009, p. 231). Nesse conto, Pórcia é a "dama de Belmonte", disfarçada de "doutor em direito", e ela solicita ao judeu (que não tem nome) que aceite o pagamento oferecido e não execute a sua garantia (a libra de carne do garantidor, Messer Ansaldo), deixando-o livre

12 Segundo Bill Bryson (2008, p. 88), "muitas são as teorias sobre onde ele [Shakespeare] passou os anos da peste de 1592 e 1593. Uma delas é que esteve viajando pela Itália, o que responderia por uma onda de peças italianas quando de sua volta", como O mercador de Veneza. 
e ganhando a sua gratidão. Ou seja, a dama de Belmonte apenas pede a misericórdia do judeu, que não a concede porque queria o julgamento. $\mathrm{E}$, um pouco antes desse trecho, o conto mostra-se adequado à natureza da civil law:

\begin{abstract}
Mas o judeu respondeu que ele não queria o dinheiro, uma vez que não tinha sido pago em tempo hábil, mas que desejava cortar a libra de carne de Ansaldo. Sobre esta matéria surgiu grande debate, e todos condenaram o judeu; mas, vendo a lei equitativa estabelecida em Veneza, e que o contrato do judeu foi totalmente estabelecido e na forma legal e habitual, ninguém poderia negar-lhe os seus direitos; tudo o que podiam fazer era implorar a sua misericórdia. (Fiorentino, 1556, p. 55) ${ }^{13}$.
\end{abstract}

Vê-se que em momento algum o conto faz qualquer alusão ao stare decisis e à força de um eventual precedente que seria criado caso o julgamento liberasse o credor da execução da garantia. Há uma referência, sim, à lei vigente em Veneza, que seria equitativa (justa) e à força dos contratos. Contextualizando a história dos precedentes na Inglaterra juntamente com $O$ mercador de Veneza, verifica-se que Shakespeare levou aos palcos a cultura jurídica que bem caracteriza o common law, o uso dos precedentes. Shakespeare não se limitou a "copiar" o conto Il Pecorone, e naquela época as tramas e personagens eram propriedade comum para os dramaturgos elisabetanos, mas "o que Shakespeare fez, é claro, foi pegar obras rasas e dotá-las de distinção e, muitas vezes, de grandeza” (Bryson, 2008, p. 100-101). O que Shakespeare fez foi "emprestar" a sua genialidade para transformar um conto medieval em uma peça de teatro única, muito superior ao conto que o antecedeu e eventualmente superior às adaptações posteriores que foram feitas da sua peça, desconhecidas hoje.

\title{
OS PRINCÍPIOS DA PROTEÇÃO DA CONFIANÇA E DA SEGURANÇA JURÍDICA ATRAVÉS DOS PRECEDENTES VINCULANTES
}

A atualização do texto de Shakespeare, na perspectiva do campo do direito processual, possibilitaria amplo leque de questões a serem investigadas, mas não é esse o propósito do presente artigo. Porém importantes questões sobre os precedentes são levantadas pelo dramaturgo,

13 A versão original está em italiano, porém foi utilizada a versão em inglês, traduzida por W. G. Waters. Neste caso, optou-se por uma tradução livre do inglês para o português. 
como as atinentes aos princípios da segurança jurídica e da proteção da confiança, entre outros. Atualmente, sabe-se que a adesão aos precedentes - decisões proferidas no passado - por juízes do presente é fundamental para possibilitar um sistema jurídico minimamente seguro. A segurança jurídica é um dos princípios basilares do stare decisis. É impensável em um sistema jurídico fortemente centrado nos precedentes, como o common law, que exista a possibilidade de casos parecidos receberem decisões diferentes porque há divergência entre os juízes acerca do direito a ser aplicado nos casos concretos. Da mesma forma que no civil law o direito legislado (a lei) é aplicado de modo uniforme a todos, no common law isso ocorre com os precedentes. Shylock queria um julgamento na certeza de que a lei seria aplicada exatamente como estava nela determinado: ele tinha absoluta confiança na obtenção de um julgamento que lhe assegurasse o direito à execução da garantia, agindo de forma segura e inflexível. Só não contava com a solução final que foi dada, é verdade, mas o mérito do "julgado" não é objeto deste trabalho, que se dedica a examinara força dos precedentes em Shakespeare.

A inflexibilidade do judeu Shylock decorre de diversos fatores que os especialistas em Shakespeare já analisaram, porém o foco aqui é a segurança jurídica, sem, entretanto, nos ocuparmos de aprofundar sua compreensão no contexto das teorias democráticas. Shylock exige um julgamento, porque sabia que o teria, não nas condições em que o recebeu, mas ele tinha essa certeza. A segurança jurídica proporciona isso aos jurisdicionados: a previsibilidade das decisões judiciais, seja porque as leis são escritas de forma clara ao definir direitos e obrigações, seja porque há precedentes anteriores que levam as partes a deduzir que eles serão utilizados na fundamentação das decisões judiciais. É corrente a afirmação de que "as decisões judiciais oferecem exemplos, guias ou critérios de interpretação do direito" (Soriano, 2002, p. 130). Segundo Gustav Radbruch, o direito não pode ficar abandonado às diferenças de opiniões dos indivíduos, e por isso faz-se necessário que haja uma ordem acima de tudo e de todos. Portanto, além da justiça e da utilidade como elementos essenciais do direito, o filósofo inclui a segurança jurídica, e "esta exige positividade do direito: se não se pode identificar o que é justo, então é necessário estabelecer o que deve ser jurídico, e de uma posição que esteja 
em condições de fazer cumprir aquilo que foi estabelecido" (Radbruch, 2004, p. 108).

Portanto, se não se pode criar uma "regra" justa e individualizada para cada situação concreta, é preciso que o direito seja imposto a todos indistintamente, seja através da lei, seja através das decisões judiciais. É certo, porém, que a certeza de Shylock em obter um julgamento que lhe fosse favorável foi até presunçosa, porque não considerou a possibilidade de alei ser interpretada de acordo com princípios jurídicos que lhe dessem sentido distinto do pretendido pela parte - como de fato ocorreu - e nem mesmo no common law, com o stare decisis, pode se ter essa certeza apenas baseado em um precedente. A utilização da fundamentação de um precedente em caso futuro não é uma operação matemática simples, exigindo que se verifique uma série de fatores que podem racionalmente justificar a não adesão ao precedente, seja porque ele deve ser superado (overruling), seja porque os casos - presente e passado - não possuem semelhanças suficientes para a aplicação das razões do precedente (distinguishing). A ideia de que a doutrina dos precedentes proporciona absoluta segurança e certeza é ilusória, segundo alguns autores, tendo em vista que ela deixa espaço suficiente para o juiz fazer uso de uma "manobra", de modo que o fato do stare decisis não é absoluto, não proporcionando certeza absoluta, mas apenas algum grau de certeza (Duxbury, 2008, p. 160).

Mesmo assim, o stare decisis proporciona "alguma” certeza, em virtude do fato de que utilização de duas de suas principais técnicas overruling e distinguishing - exige fundamentação específica e adequada, não podendo pura e simplesmente ser argumentado pelo juiz no caso concreto que deixa de seguir um precedente. Portanto, se a decisão judicial deve ser racionalmente fundamentada, em todos os seus aspectos, ou seja, se é dever do juiz expor as razões pelas quais está aderindo ao precedente ou se apartando dele, o sistema proporciona uma segurança jurídica suficiente para que "surpresas" não ocorram. Conforme assentado pela Suprema Corte dos Estados Unidos da América, no caso Kimble vs Marvel Entertainment, $L L C$, “o que a gente pode decidir, pode voltar atrás. Mas o stare decisis nos ensina que devemos exercer essa autoridade com 
moderação"14. Na peça de Shakespeare, ao afirmar, no decorrer do julgamento, não ser possível substituir a execução da garantia da promissória pelo pagamento, já que o credor (Shylock) não havia recebido o pagamento no prazo e preferia executar sua garantia, Pórcia defende que, caso a Corte autorizasse essa substituição, essa decisão iria criar um precedente capaz de pautar a conduta da sociedade, posto que choveriam ações legais equivocadas. Trata-se, segundo se pensa, de uma manifestação do princípio da proteção da confiança.

O direito incorpora a história do desenvolvimento de uma nação através de muitos séculos e não pode ser tratado como se contivesse apenas os axiomas e corolários de um livro de matemática (Holmes, 2005, p. 3), mas mesmo assim todo sistema jurídico tem a pretensão de ordenação e unidade. Enquanto a primeira busca exprimir um estado de coisas intrínseco $\mathrm{w}$ racionalmente apreensível, isto é, fundado na realidade; a segunda busca não permitir dispersões numa diversidade de singularidades desconexas (Canaris, 2012, p. 12-13). Isso ocorre, seja num sistema codificado como o civil law, ou não, como o da common law, em que não há uma compilação abrangente de normas legais e estatutos. Na common law há leis escritas, porém se trata de um sistema em grande parte baseado em precedentes, e esses precedentes pautam a conduta das sociedades dos países que o adotam. Assim como um cidadão de país civil law pauta - ou pelo menos deveria pautar - sua conduta pelas leis, um cidadão da common law o faz - ou deveria fazer - pelo que os precedentes dizem. Ambos devem - ou deveriam - pautar suas condutas pelo direito, porém com a distinção acima referida. Referindo-se ao sistema civil law, mas perfeitamente aplicável ao common law, Gometz afirma que

[...] a certeza do direito nasce como previsibilidade (exata) alcançada mediante o conhecimento de uma legislação clara, exígua, completa, consistente e acima de tudo, pública: todos os indivíduos podem conhecer a lei, logo todos os indivíduos podem aproveitar as vantagens da possibilidade de programar estrategicamente os seus próprios comportamentos, de modo que tenham em conta as consequências jurídicas que isso implica (Gometz, 2012, p. 222).

\footnotetext{
14 Disponível em: <https://www.supremecourt.gov/opinions/14pdf/13-720_jiel.pdf $>$. Acesso em: 5 set. 2016.
} 
Portanto, uma decisão judicial tem importância significativa na sociedade common law porque aquilo que é decidido nos casos concretos também "decide" como devem os cidadãos, fora do processo, agir. Um princípio jurídico enunciado em um precedente, além de servir de fundamento para a decisão proferida, também serve como princípio fora daquele processo, não só determinando como os juízes devem julgar as causas semelhantes futuramente, mas também como se espera que os cidadãos ajam. Assim sendo, um princípio relacionado ao direito civil, no campo dos contratos, como o da "impossibilidade de substituição da execução da garantia pelo pagamento, quando se pretende realizá-lo depois do vencimento da obrigação", tem função extraprocessual muito importante, porque credores e devedores em situação assemelhada geralmente se comportam dessa forma. Ou seja, é lícito ao credor recusar o pagamento, quando oferecido fora do prazo, para pretender receber a garantia contratual estipulada. Como bem observado, acerca da proteção da confiança:

A segurança jurídica abrange também o princípio da
confiança legítima, que prevê que "aqueles que agem de
forma razoável e de boa fé com base na lei como ela é, ou
pelo menos parece ser, não deve sofrer de decepção
dessas expectativas". Neste sentido, as expectativas
legítimas protegem o status legal de um cidadão, contra
as autoridades que criaram uma situação, por um período
considerável de tempo, em que os cidadãos podem
confiar (Godínez, 2015, p. 14).

Se em uma demanda fica estabelecido esse princípio, sabe-se que casos futuros serão julgados exatamente dessa forma, com a aplicação desse princípio, desde que os casos possuam semelhanças suficientes para ensejar a aplicação do mesmo princípio enunciado no precedente. Isso tende a desestimular a propositura de ações de devedores que querem pagar, apesar do prazo vencido, para evitar a execução da garantia. Se uma decisão judicial enuncia que é possível ao devedor pagar, mesmo que fora do prazo, para evitar a execução da garantia, da mesma forma isso gera um efeito extraprocessual. Seja qual fosse a decisão do caso Shylock $v$ Antonio, ela iria gerar uma consequência fora do processo, e por isso mesmo Antonio sabia que o Doge não podia impedir o curso da lei, uma vez que ele "compreende a importância do cumprimento das regras para o Estado, notadamente para que os mercadores de toda parte possam confiar em 
Veneza", bem como tinha a exata noção do stare decisis "tão preciosa ao sistema da 'common law'. O respeito do julgador à decisão precedente é fundamental para garantir a segurança social” (Neves, 2016, p. 142).

Em suma: o direito precisa gerar segurança jurídica. Seja pelas leis, seja pelas decisões judiciais, o direito cumpre essa crucial função social. No common law, que adota o sistema de precedentes (stare decisis), as decisões judiciais - em um ou outro sentido - enunciam regras de direito que pautam condutas, podendo evitar ou estimular a propositura de demandas. Atualmente, é comum associar o stare decisis à postura a ser adotada por alguém que queira, eventualmente, litigar em uma Corte, de modo que as regras de direito enunciadas nas decisões judiciais produzem efeitos econômicos, como o de fornecer "um sinal valioso para futuros litigantes" (Macey, 1989, p. 106). Lord Neuberger, Presidente da Suprema Corte do Reino Unido, em discurso proferido em 2016, disse o mesmo que Shakespeare em 1597, afirmando que os juízes do common law não decidem simplesmente os casos que lhe são submetidos porque suas decisões são parte do direito vigente no país (law of the land). Pontua o Lord que, "ao decidir uma questão de direito, um juiz deveria se lembrar que todos os potenciais futuros litigantes vão procurar seus advogados para aconselhamento" (Neuberger, 2016, p. 7).

$\mathrm{E}$, a partir do momento que as pessoas fazem e deixam de fazer coisas para se adequar aos princípios enunciados nos precedentes, estão agindo com confiança no sistema. O Supremo Tribunal Federal, no Brasil, já decidiu que o princípio da confiança é elemento da segurança jurídica ${ }^{15}$. E na doutrina encontra-se a mesma formulação, sendo que confiança legítima significa que o Poder Público não deve frustrar, deliberadamente, a justa expectativa que tenha criado no administrado ou no jurisdicionado (Barroso, 2005, p. 22). Igual teor tem a preocupação de Pórcia com aquilo que eventualmente viesse a ser decidido no caso Shylock, tendo em vista que uma decisão que autorizasse a substituição da execução da garantia pelo pagamento fora do prazo iria gerar uma expectativa em todos os devedores no mesmo sentido, estimulando uma chuva de ações legais.

15 Por exemplo: STF, MS 24268, Relatora Min. Ellen Gracie, Relator p/ Acórdão Min. Gilmar Mendes, Tribunal Pleno, julgado em 05/02/2004, DJ 17.09.2004. 
A adesão aos precedentes, e aos princípios neles enunciados, não significa, por óbvio, a sua “eternização”. O Ministro Luís Roberto Barroso, em momento anterior à sua nomeação para a mais alta Corte do Brasil, já havia escrito e concluído que

\begin{abstract}
A ascensão doutrinária e normativa do procedente não o torna imutável. Mas impõe maior deferência e cautela na sua superação. Quando uma corte de justiça, notadamente o Supremo Tribunal Federal, toma a decisão grave de reverter uma jurisprudência consolidada, não pode nem deve fazê-lo com indiferença em relação à segurança jurídica, às expectativas de direito por ele próprio gerada, à boa-fé e à confiança dos jurisdicionados. Em situações como esta, é a própria credibilidade da mais alta corte que está em questão (Barroso, 2005, p. 15)
\end{abstract}

A técnica do overruling existe exatamente para permitir que a tese jurídica enunciada em um precedente seja afastada pelo Tribunal, promovendo-se a sua superação, porém através de uma fundamentação específica e racional. Com isso impede-se a mudança de opinião da Corte apenas porque o caso precedente foi decidido de forma equivocada. Como já observado, o stare decisis não permite que um juiz altere o entendimento enunciado em casos anteriores apenas porque ele acredita que os casos anteriores foram decididos de forma equivocada (Brenner; Spaeth, 2003, p. 8). Portanto, exige-se bastante moderação para a prática do overruling, porque uma mudança de entendimento afeta a confiança que a população deposita no Judiciário, através dos seus precedentes, para poder pautar suas condutas. Seja um entendimento de direito material, seja de direito processual, há uma legítima expectativa de que determinada conduta tenha o respaldo do Judiciário. Se um devedor não consegue se ver livre da sua obrigação, pagando após o vencimento e permitindo assim a execução da garantia, exatamente na forma como os precedentes estabelecem como sendo o justo e o correto para a questão, tem-se a legítima expectativa de esperar que seja decidido da mesma forma em casos futuros. Portanto, a preocupação com a possibilidade de se abrir uma exceção foi muito bem delineada na peça de Shakespeare com o justo receio de que tal prática pudesse colocar em risco a confiança que as pessoas depositam no sistema judicial de um país. Por isso invoca-se aqui a genialidade de Shakespeare em expressar a preocupação de Antonio, na virada do século XVI para o XVII, com o cumprimento da lei, expondo que as garantias que os 
estrangeiros encontram em Veneza (segurança jurídica) não poderiam ser suspensas, sob pena de a confiança no Estado ficar abalada perante os olhos de todos.

Não que modificações de tese não possam ser feitas. Muito pelo contrário, elas devem ser feitas, desde que estejam presentes condições legítimas para sustentar essa mudança e argumentos razoáveis, porém o overruling deve ser feito com muita cautela, por força da proteção da confiança. E mesmo que, na peça de Shakespeare, o julgamento do precedente Shylock vs Antonio não tenha sido exatamente como esperava o credor - e ele expressou a sua confiança em obter um julgamento porque acreditava que o direito lhe protegia no caso concreto -, tem-se mesmo assim um excepcional exemplo da força dos precedentes. A decisão final guarda uma particularidade ímpar, consistente na garantia da libra da carne, uma vez que executada a garantia, Antonio certamente teria morrido, de tal modo que, se fosse outra a garantia, talvez o resultado do julgamento também tivesse sido outro. O respeito aos precedentes, como afirmado anteriormente, não é mera operação matemática, mas exige que as circunstâncias específicas do caso concreto sejam consideradas séria e detidamente pelo órgão julgador. Em $O$ mercador de Veneza, mesmo não tendo sido alcançado o resultado desejado por Shylock, a segurança jurídica estaria preservada na ocasião em que, em julgamento futuro, o precedente Shylock VS Antonio fosse invocado por um credor interessado em cobrar a garantia do fiador, bastando a ele mostrar a profunda distinção entre o seu caso e o anterior. Esse credor poderia, por exemplo, querer a execução da sua garantia, consistente em alguns bens móveis ou imóveis, e poderia invocar o precedente exatamente para mostrar que é direito do credor executar a garantia, salvo quando ela não atentar contra a vida do garantidor. Da mesma forma, um fiador que pretendesse se ver livre da sua garantia, ou encontraria apoio no precedente, caso a garantia atentasse contra a sua vida, ou não, caso a garantia fosse "normal".

\section{CONCLUSÕES}

William Shakespeare é/foi genial, filosoficamente imortal, porque passados 400 anos do seu falecimento sua obra ainda é lida, estudada e interpretada, de modo que o "ser" pereceu, mas a "obra”, o "legado", é 
eterno. Esse trabalho analisa apenas um dos traços da genialidade desse dramaturgo, que é a sua capacidade de antecipar temas que seriam debatidos séculos depois. Muito já se escreveu sobre suas peças, seus sonetos, sua vida etc, porém cada leitura que se faz abre novas possibilidades de interpretação e compreensão da profundidade e extensão do seu legado. Provavelmente ainda há muito a ser descoberto sobre ele e sua obra, e a referência aos precedentes na cena do julgamento de Shylock revela que ele não era alheio ao sistema de justiça praticado na Inglaterra, no final do século XVI.

Sobre a força dos precedentes, já é de se louvar que um juiz, um jurista reconhecido até hoje como fundamental para o desenvolvimento da common law, como Sir Edward Coke, tenha feito uso dos precedentes na fundamentação das suas decisões durante o período que funcionou como Chief Justice na Court of Common Pleas. Se um jurista merece todo o reconhecimento por ter sido pioneiro e inovador no exercício da sua função, o que se pode dizer de William Shakespeare? O dramaturgo simplesmente conseguiu em sua obra $O$ mercador de Veneza representar a importância da adesão aos precedentes, em conjunto com os princípios da segurança jurídica e da proteção da confiança.

\section{REFERÊNCIAS}

BARROSO, Luís Roberto. Mudança da jurisprudência do Supremo Tribunal Federal em matéria tributária. Segurança jurídica e modulação dos efeitos temporais das decisões judiciais. Disponível em: $<$ http://www.luisrobertobarroso.com.br/wpcontent/themes/LRB/pdf/parecer mudanca da jurisprudencia do stf.p df $>$. Acesso em: 22 ago. 2016.

BRENNER, Saul; SPAETH, Harold J. Stare indecisis - the alteration of precedent on the Supreme Court, 1946-1992. Cambridge: Cambridge University Press, 2003.

BRYSON, Bill. O mundo é um palco; uma biografia. Trad. de José Rubens Siqueira. São Paulo: Companhia das Letras, 2008.

CANARIS, Claus-Wilhelm. Pensamento sistemático e conceito de sistema na ciência do direito. 5. ed. Trad. de A. Menezes Cordeiro. Lisboa: Calouste Gulbenkian, 2012.

COKE, Sir Edward. The Reports of Sir Edward Coke, vol. IV. London: Joseph Butterworth and Son, 1826. Disponível em: <http://books.google.co.uk/books?id=PlYDAAAAQAAJ > . Acesso em: 24 ago. 2016. 
COWNIE, Fiona et al. English legal system in context. 4. ed. Oxford: Oxford University Press, 2007.

CROSS, Rupert; HARRIS, J. W. Precedent in english law. Oxford: Claredon Press, 2004.

DUXBURY, Neil. The nature and authority of precedent. Cambridge: Cambridge University Press, 2008.

FIORENTINO, Ser Giannetto. The Pecorone. Disponível em: $<$ https://archive.org/stream/pecoroneofsergiooogiovrich/pecoroneofsergi ooogiovrich djvu.txt>. Acesso em: 31 ago. 2016.

FRAGALE FILHO, Roberto da Silva; LYNCH, Christian Edward Cyril. Shylock vs. Antonio (1594): dois olhares. Disponível em: <http://www.casaruibarbosa.gov.br/escritos/numero02/FCRB Escritos 2 13 Roberto da Silva Fragale Filho e Christian Edward Cyril Lynch .pdf $>$.Acesso em: 17 jun. 2016.

GHIRARDI, José Garcez. Somos todos rematados canalhas: notas sobre vingança e justiça em Shakespeare. Anamorphosis - Revista Internacional de Direito e Literatura.v. 1, n. 1, p. 85-98, jan.-jun. 2015. http://dx.doi.org/10.21119/anamps.11.85-98

GODÍNEZ, Rafael Quintero. Stare decisis, legal certainty and the concept of economic activity, regarding the VAT treatment of public bodies. Master Thesis on Master's Programme in European and International Tax Law 2014/2015. Disponível em: <http://lup.lub.lu.se/luur/download?func $=$ downloadFile\&recordOId $=54.35$ 338\&fileOId $=7357656$ > . Acesso em: 30 ago. 2016.

GOMETZ, Gianmarco. La certeza jurídica como previsibilidad. Trad. de Diego Cruz e Diego Vechhi. Madrid: Marcial Pons, 2012.

HALE, Matthew. The history of the common law. Chicago: The University of Chicago Press, 1971.

HELIODORA, Barbara. Falando de Shakespeare. São Paulo: Perspectiva, 2009.

HELIODORA, Barbara. Shakespeare; o que as peças contam. Rio de Janeiro: Edições de Janeiro, 2014.

HOGUE, Arthur R. Origins of the common law. Indianapolis: Liberty Fund, 1985 .

HOLMES, Oliver Wendell. The common law. Stilwell: Digireads.com Publishing, 2005.

HULSEBOSCH, Daniel. The ancient constitution and the expanding empire: Sir Edward Coke's british jurisprudence. Law and history review, v. 21, n. 3, p. 439-482, 2003.https://doi.org/10.2307/3595117

MACEY, Jonathan R. The internal and external costs and benefits of stare decisis. Yale Law School Legal Scholarship Repository, Paper 1744, 1989. Disponível em: $<\underline{\text { http://digitalcommons.law.yale.edu/cgi/viewcontent.cgi?article }=2762 \& c 0}$ ntext=fss papers $>$. Acesso em: 30 ago. 2016. 
NEUBERGER, Lord. The role of the judge: umpire in a contest, seeker of the truth or something in between? Singapore Panel on Judicial Ethics and Dilemmas on the Bench: Opening Remarks, 19 August 2016. Disponível em: $<$ https://www.supremecourt.uk/docs/speech-160819-04.pdf $>$. Acesso em: 5 set. 2016.

NEVES, José Roberto de Castro. Medida por medida: o direito em Shakespeare. 5. ed. Rio de Janeiro: Edições de Janeiro, 2016.

NOGUEIRA, Gustavo Santana. Sir Edward Coke e o judicial review inglês: breve história. In: DIDIER JR., Fredie (Coord.). Teoria do processo; panorama doutrinário mundial, segunda série. Salvador: JusPodivm, 2010. p. 307-324.

PLUCKNETT, Theodore. A concise history of the common law. Indianapolis: Liberty Fund, 1956.

POLLOCK, Sir Frederick; MAITLAND, Frederic Willian. The history of english law; before the time of Edward I. Cambrige: Cambdrige University Press, 1898.

RADBRUCH, Gustav. Filosofia do direito. Trad. de Marlene Holzhausen. São Paulo: Martins Fontes, 2004.

SEGADO, Francisco Fernández. Sir Edward Coke, El Bonham's Case y la Judicial Review. Observatório da jurisdição constitucional, ano 6, n. 2, p. 167-236, jul./dez. 2013. Disponível em: <https://www.portaldeperiodicos.idp.edu.br/observatorio/article/view/91 3/620 >. Acesso em: 24 ago. 2016.

SHAKESPEARE, William. O mercador de Veneza. Trad. de Beatriz ViégasFaria. Porto Alegre: L\&PM, 2010.

SHAKESPEARE, William. The merchant of Venice; A contemporary english version, emended and rectified with notes and commentary by Jonathan Star. Disponível em: <http://uppcolleges.com/wpcontent/uploads/2015/04/merchant of venice 12.pdf $>$. Acesso em: 19 ago. 2016.

SORIANO, Leonor Moral. El precedente judicial. Madrid: Marcial Pons, 2002.

TRINDADE, André Karam. Entre pequenas injustiças e grandes justiças: "O mercador de Veneza” e a representação do juiz. In: STRECK, Lenio Luiz; TRINDADE, André Karam (Org.). Os modelos de juiz; ensaios de direito e literatura. São Paulo: Atlas, 2015.

YOSHINO, Kenji. Mil vezes mais justo; o que as peças de Shakespeare nos ensinam sobre a justiça. Trad. de Fernando Santos. São Paulo: Martins Fontes, 2014. 